\title{
Peculiarities of Phase Formation in Artificial Ceramic Binders for White-Ware Compositions
}

\author{
I. Moreva ${ }^{(\bowtie)}$, E. Evtushenko, O. Sysa, and V. Bedina \\ Belgorod State Technological University named after V G Shukhov, \\ Belgorod, Russia \\ moreva_bstu@mail.ru
}

\begin{abstract}
The production of sanitary white wares traditionally uses multicomponent mixes, which is necessitated by a whole complex of properties: high density and low humidity of molding slurries with low thixotropic strengthening and good filterability of the slurry. However, modern understanding of the structure and properties of materials open opportunities for optimization of technological process and production of higher-quality articles. The implementation of activation technologies and replacement of traditional molding slurries by artificial ceramic binders will reduce the number of components in mixes and optimize the production of white wares. Since the achievement of working performance of ceramic materials substantially depends on the phase formation processes in a material during sintering. Current work analyses the phase transformations occurring at all stages of white ware production as per proposed technology.
\end{abstract}

Keywords: Artificial ceramic binders - Phase conversions - Porcelain · Pottery $\cdot$ Ceramic slurry

\section{Introduction}

Artificial ceramic binders (ACBs) are molding suspensions produced by the technology of high-concentration ceramic binding suspensions (Pivinskii 2003) from nonplastic materials (quartz sand, quartz glass, fire clay, etc.). The binding properties of such suspensions are determined not by clay minerals (as in the case of traditional ceramic slurries), but by a colloid component that forms during milling and which content can reach up to 5\%. Previous studies have shown the possible production of ACBs on the basis of clay materials after preliminary thermal activation. The technology allows producing high-density molding suspensions with record-low moisture content: Wsusp $=16 \%, \rho=1950 \mathrm{~kg} / \mathrm{m}^{3}$ (for traditional slurry $35 \%$ and $1740 \mathrm{~kg} / \mathrm{m}^{3}$, respectively). This technology is interesting for the production of white wares, because it allows unifying the properties of implemented raw materials and reduce the number of components in the paste from more than 7 down to 3 . This work studies the peculiarities of ACB formation on the basis of thermally activated mixes of typical white ware composition: $50 \%$ of clay (kaolin from Prosyanoye deposit), $25 \%$ of fluxes (Vishnevogorsk spar) and $25 \%$ of filling aggregates (Ziborovsk sand). 


\section{Methods and Approaches}

Initial materials were broken, mixed and wetted to $15-20 \%$ with consequent formation of bricks. After drying, the bricks were burnt at the temperature of $950-1000{ }^{\circ} \mathrm{C}$ with shock cooling for increased system activity. The thermally activated mix was milled as per the technology of highly concentrated ceramic binders for suspensions with introduction of electrolytes and liquid phase at the loading of the first part of the material. The XRD analysis of the investigated materials was made on DRON-3 diffractometer. The diffractograms were recorded with filtered $\mathrm{CuK} \alpha$-radiation ( $\mathrm{Ni}$ filter); the tube voltage was $20 \mathrm{kV}$; tube anode current was $20 \mathrm{~mA}$; the measurement limit was 10,000 4,000 pulses per second; the detector rotation speed was $2.4 \mathrm{~min}^{-1}$; the angular mark was 10 . The phases were identified using JCPDF cards. The samples with the dimensions of $30 \times 30 \times 30 \mathrm{~mm}$ from obtained suspensions and slurries were formed by molding into gypsum molds. The dried samples were burnt in a periodic kiln with silicon carbide heating elements at the temperature of $800-1200{ }^{\circ} \mathrm{C}$ with holding at maximum temperature for 5-10 min.

\section{Results and Discussion}

The preliminary thermal treatment of the studied raw materials allowed weakening crystal lattices of the minerals, creating the structural non-stability due to polymorph transformations of quartz $(\mathrm{d} / \mathrm{n}, \AA-4.27 ; 3.35 ; 2.46 ; 2.29)$ and dehydration of clay and hydromicaceous minerals $(\mathrm{d} / \mathrm{n}, \AA-7.23 ; 3.36 ; 4.48 ; \mathrm{d} / \mathrm{n}, \AA-10.16 ; 3.30 ; 2.91)$ (Fig. 1). After such a thermal treatment, a part of material passes into active state (Evtushenko et al. 2007).

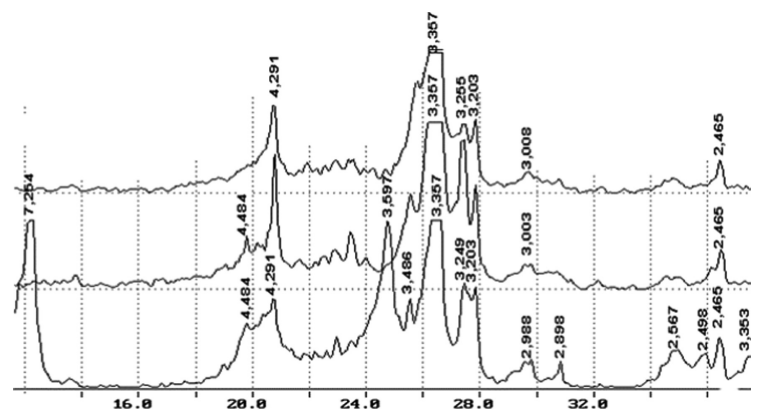

Fig. 1. Changed phase composition of studied mixes after activation and consequent milling: (a) initial untreated mix; (b) mix after thermal activation at $950{ }^{\circ} \mathrm{C}$; (c) after wet milling.

The preliminary thermal activation of the material, consequent wet milling and high density of the samples facilitates the intensification of burning, in particular, appearance of mullite seeds $(\mathrm{d} / \mathrm{n}, \AA-3.39 ; 5.42 ; 2.71 ; 2.55)$ beginning from $950{ }^{\circ} \mathrm{C}$. In traditional compounds, the formation of mullite begins only at $1100{ }^{\circ} \mathrm{C}$. A part of 
crystalline phases of the ACB in the white ware composition transits into the melt, which is witnessed by the appearance of amorphous phase and decrease in the intensity of reflections that are typical for quartz $(\mathrm{d} / \mathrm{n}, \AA-3.35 ; 4.27 ; 2.46)$ and feldspars (d/n, $\AA-3.24 ; 3.22$ ) (Fig. 2).

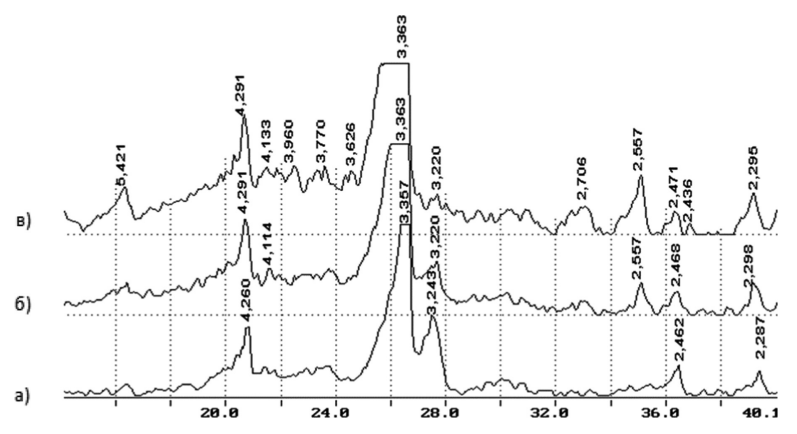

Fig. 2. X-ray diagrams of burnt samples of $\mathrm{ACB}$ in white ware composition: (1) $950{ }^{\circ} \mathrm{C}$; (2) $1100{ }^{\circ} \mathrm{C}$; (3) $1200{ }^{\circ} \mathrm{C}$

Probably, a denser structure of the molding leads to an intense amorphization and sintering at temperatures close to $1100{ }^{\circ} \mathrm{C}$, while at $1200{ }^{\circ} \mathrm{C}$ close-packed structures start to crystallize and stabilize. The high intensity of sintering and formation of a stronger structure of ACB samples is testified by gradual increase in the coefficient of crystallinity (Cc) with increased burning temperature: from $58.5 \%$ at $600{ }^{\circ} \mathrm{C}$ up to $91 \%$ at $1200{ }^{\circ} \mathrm{C}$, while for cement plant slurry it is $66.5 \%$ at the final burning temperature. The high values of $\mathrm{Cc}$ for samples of $\mathrm{ACB}$ are probably connected with more intense processes of mullite and cristobalite formation.

\section{Conclusions}

Thus, the revealed peculiarities of phase formation in ACBs of white ware compositions demonstrate that the material has high reactivity in a wide temperature range. The preliminary thermal activation of raw materials with consequent sintering of the material facilitates earlier beginning of mullite and melt formation. The mentioned processes are determining for the formation of the strong structure of the material and high operation characteristics of the ceramic products.

Acknowledgements. The work is realized in the framework of the Program of flagship university development on the base of Belgorod State Technological University named after V.G. Shoukhov, using equipment of High Technology Center at BSTU named after V.G. Shoukhov. 


\section{References}

Evtushenko EI, Sysa OK, Moreva IYu (2007) Controlling the properties of raw materials, casting slips, and pastes in fine-ceramic technology. Stroit Mater 8:16-17

Pivinskii YuE (2003) Highly concentrated ceramic binding suspensions (HCBS) and ceramic castables. Stages in research and development. Refract Ind Ceram 44(3):152-160

Open Access This chapter is licensed under the terms of the Creative Commons Attribution 4.0 International License (http://creativecommons.org/licenses/by/4.0/), which permits use, sharing, adaptation, distribution and reproduction in any medium or format, as long as you give appropriate credit to the original author(s) and the source, provide a link to the Creative Commons license and indicate if changes were made.

The images or other third party material in this chapter are included in the chapter's Creative Commons license, unless indicated otherwise in a credit line to the material. If material is not included in the chapter's Creative Commons license and your intended use is not permitted by statutory regulation or exceeds the permitted use, you will need to obtain permission directly from the copyright holder. 